\title{
High Carbonated Soft Drink Intake is Associated with Health Risk Behavior and Poor Mental Health among School-Going Adolescents in Six Southeast Asian Countries
}

\author{
Supa Pengpid ${ }^{1,2}$ and Karl Peltzer ${ }^{2, *}$ \\ 1 ASEAN Institute for Health Development, Mahidol University, Salaya, Phutthamonthon, \\ Nakhonpathom 73170, Thailand; supaprom@yahoo.com \\ 2 Lifestyle Diseases Research Entity, Faculty of Health Sciences, North-West University, Mafikeng Campus, \\ Mmabatho 2745, South Africa \\ * Correspondence: kfpeltzer@gmail.com
}

Received: 26 November 2019; Accepted: 20 December 2019; Published: 23 December 2019

\begin{abstract}
Carbonated soft drink (CSD) intake has been associated with various risk behaviors in adolescents in high-income countries, but there is lack of evidence of this association in cross-nationally representative samples of school adolescents in low- and middle-income countries. This study aimed to assess the association between CSD intake, health risk behavior, and poor mental health behavior among school-going adolescents in six Southeast Asian countries. Cross-sectional national "Global School-Based Student Health Survey (GSHS)" data from 36173 school-going adolescents from Bangladesh, Indonesia, Laos, Philippines, Thailand, and Timor-Leste were analyzed. Results indicate that across all six Southeast Asian countries, in the past 30 days $23.9 \%$ of study participants had consumed no CSD, $38.8 \%$ had consumed CSD <once/day, $19.9 \%$ once a day and $17.5 \% \geq$ two times/day. In the final adjusted logistic regression model CSD intake was associated with increased odds of having been attacked, having sustained an injury, being in a physical fight, being bullied, school truancy, tobacco use, alcohol use, and lifetime drunkenness. In addition, the consumption of CSD $\geq$ two times/day was associated with increased odds of ever used cannabis and ever used amphetamine. Higher intake of CSD was positively associated with a history of loneliness, anxiety, suicide ideation, suicide planning, and suicide attempts. CSD intake in low- and middle-income countries is associated with several health risk behaviors and poor mental health that are similar to those observed in high-income countries.
\end{abstract}

Keywords: soft drink intake; aggressive behavior; substance use; psychological distress; adolescents; Southeast Asia

\section{Introduction}

Carbonated soft drink (CSD) intake has been linked with excess body weight, medical, and oral health problems [1,2]. Relatively little is known of the association between CSD intake and health compromising behavior [3]. Several studies on CSD intake, mainly in high-income countries, found associations between CSD intake and health compromising behaviors.

In studies of American school-going adolescents, higher CSD consumption increased the odds for physical fighting, aggressive behavior [4,5], and substance use [5,6]. In addition, CSD intake was associated with poor mental health, such as depressive symptoms $[4,6,7]$ and suicidal behavior [4]. In school-going adolescents in China, CSD intake was associated with suicidal behavior [8]. In school students in Korea CSD intake was associated with poorer general and mental health [9]; and in an 
investigation in middle-school students in Malaysia, CSD intake was associated with injury [10]. In a study of adolescents in 26 high-income countries in Europe, sugar consumption increased the odds for health risk behaviors, including substance use (alcohol and cigarettes), physical fighting, and bullying [3].

For optimal physical and mental development during adolescence a balanced diet is vital, and therefore it is of public health concern to understand the relationship between CSD intake and health risk behavior and poor mental health [3]. There is a lack of cross-national studies on the relationship between CSD intake and health compromising behaviors in low- and middle-income countries. The study aimed to assess associations between CSD intake and health risk behavior and poor mental health among school-going adolescents in six Southeast Asian countries.

\section{Method}

\subsection{Sample and Procedure}

This study is a secondary analysis of cross-sectional national data from six Southeast Asian countries collected in 2014-2015 World Health Organization (WHO) “Global School-based Student Health Survey (GSHS)". Details about the WHO GSHS methodology and its data can be publicly accessed [11]. Briefly, the GSHS uses a cluster sampling design in two stages (schools were selected by probability to size sampling and random selection of class rooms with students 13 to 17 years old) in order to produce nationally representative samples of school children in middle schools in each study country [11]. All students attending a selected class were eligible to participate, regardless of their age, and completed a self-administered questionnaire on a computer scannable answer sheet in their language under the supervision of trained external survey administrators [11]. Ethics review boards in each country approved the GSHS, and informed consent was obtained from the students, parents, and/or school authorities [11].

\subsection{Measures}

The survey parameters of the GSHS are described in detail in Table 1 [11]. Overweight is "defined as more than +1 standard deviation (SD) from the median body mass index by age and sex, and underweight less than -2SD from median for BMI by age and sex" [11]. Parental or guardian support items were grouped into three levels of support (low $=0-1$, medium $=2$, and high $=3-4$ ).

\subsection{Statistical Analysis}

Logistic regression analysis was used to estimate the relationship between CSD intake and a number of behavior outcomes separately. In the first model the outcome was adjusted for country and in the second model the outcome was adjusted for country, sex, age, hunger (a proxy for socioeconomic atatus), body weight, peer support, and parental support. Cases with missing data were excluded. All statistical operations were conducted with "STATA software version 15.0 (Stata Corporation, College Station, TX, USA)", adjusting for the complex study design. 
Table 1. Global school-based Student Health Survey variables, questions, and response options evaluated in this study of 2014-2015 respondents.

\begin{tabular}{|c|c|c|}
\hline Variables & Question & Response Options \\
\hline Age & "How old are you?" & "11 years old or younger to 18 years old or older" \\
\hline Sex & "What is your sex?" & "Male, Female" \\
\hline Hunger & "During the past 30 days, how often did you go hungry because there was not enough food in your home?" & $" 1=$ never to $5=$ always $(\operatorname{coded} 1-3=0 \text { and } 4-5=1)^{\prime \prime}$ \\
\hline Soft drinks & $\begin{array}{l}\text { "During the past } 30 \text { days, how many times per day did you usually drink carbonated soft drinks, such as ... } \\
\text { country specific names?" }\end{array}$ & $" 1=$ not in the past days to $7=5$ or more times per day $(\operatorname{coded} 1=1,2=2,3=3$ and $4-7=4) "$ \\
\hline \multicolumn{3}{|c|}{ Health risk behavior } \\
\hline In a physical fight & "During the past 12 months, how many times were you in a physical fight?" & " $1=0$ times to $8=12$ or more times $(\operatorname{coded} 1=0 \text { and } 2-8=1)^{\prime \prime}$ \\
\hline Physically attacked & "During the past 12 months, how many times were you physically attacked?" & " $1=0$ times to $8=12$ or more times $(\operatorname{coded} 1=0$ and $2-8=1) "$ \\
\hline Injury & "During the past 12 months, how many times were you seriously injured?" & " $1=0$ times to $8=12$ or more times $(\operatorname{coded} 1=0$ and $2-8=1) "$ \\
\hline Bullied & "During the past 30 days, on how many days were you bullied?" & $" 1=0$ days to $7=$ All 30 days $(\operatorname{coded} 1=0$ and $2-7=1) "$ \\
\hline School truancy & "During the past 30 days, on how many days did you miss classes or school without permission?" & " $1=0$ days to $5=10$ or more days $(\operatorname{coded} 1=0$ and $2-5=1) "$ \\
\hline Current tobacco use & $\begin{array}{l}\text { "During the past } 30 \text { days, on how many days did you smoke cigarettes/use any tobacco products other than } \\
\text { cigarettes, such as pipes, roll your own cigarettes, or smokeless tobacco?" }\end{array}$ & " $1=0$ days to $7=$ All 30 days $(\operatorname{coded} 1=0$ and $2-7=1) "$ \\
\hline Alcohol use & "During the past 30 days, on how many days did you have at least one drink containing alcohol?" & $" 1=0$ days to $7=$ All 30 days" \\
\hline Drunkenness & "During the past 30 days, on the days you drink alcohol, how many drinks did you usually drink per day?" & $" 1=$ Not drink in the past 30 days to $7=5$ or more drinks (coded $1-3=0$ and $4-7=1) "$ \\
\hline Cannabis use & “During your life, how many times have you used marijuana (also called country specific names)?" & " $1=0$ times to $5=20$ or more times $(\operatorname{coded} 1=0$ and $2-5=1)$ " \\
\hline Amphetamine use & $\begin{array}{l}\text { "During your life, how many times have you used amphetamines or methamphetamines (also called country } \\
\text { specific names)?" }\end{array}$ & " $1=0$ times to $5=20$ or more times $(\operatorname{coded} 1=0$ and $2-5=1)$ " \\
\hline \multicolumn{3}{|c|}{ Mental health } \\
\hline Loneliness & "During the past 12 months, how often have you felt lonely?" & " $1=$ never to $5=$ always $(\operatorname{coded} 1-3=0$ and $4-5=1) "$ \\
\hline Anxiety & $\begin{array}{l}\text { "During the past } 12 \text { months, how often have you been so worried about something that you could not sleep } \\
\text { at night?" }\end{array}$ & " $1=$ never to $5=$ always $(\operatorname{coded} 1-3=0 \text { and } 4-5=1)^{\prime \prime}$ \\
\hline Suicide ideation & “During the past 12 months, did you ever seriously consider attempting suicide?" & "Yes, No" \\
\hline Suicide plan & "During the past 12 months, did you make a plan about how you would attempt suicide?" & "Yes, $\mathrm{No}^{\prime}$ \\
\hline Suicide attempt & "During the past 12 months, how many times did you actually attempt suicide?" & " $1=0$ times to $5=6$ or more times $(\operatorname{coded} 1=0$ and $2-5=1)$ " \\
\hline \multicolumn{3}{|c|}{ Confounding factors } \\
\hline Peer support & "During the past 30 days, how often were most of the students in your school kind and helpful?" & " $1=$ never to $5=$ always $(\operatorname{coded} 1-3=0 \text { and } 4-5=1)^{\prime \prime}$ \\
\hline Parental supervision & "During the past 30 days, how often did your parents orguardians check to see if your homework was done?" & $" 1=$ never to $5=$ always $(\operatorname{coded} 1-3=0$ and $4-5=1) "$ \\
\hline Parental connectedness & "During the past 30 days, how often did your parents orguardians understand your problems and worries?" & $" 1=$ never to $5=$ always $(\operatorname{coded} 1-3=0 \text { and } 4-5=1)^{\prime \prime}$ \\
\hline Parental bonding & $\begin{array}{l}\text { "During the past } 30 \text { days, how often did your parents or guardians really know what you were doing with your } \\
\text { free time? }\end{array}$ & $" 1=$ never to $5=$ always $(\operatorname{coded} 1-3=0$ and $4-5=1) "$ \\
\hline Parental respect for privacy & $\begin{array}{l}\text { "During the past } 30 \text { days, how often did your parents or guardians go through your things without } \\
\text { your approval?" }\end{array}$ & $" 1=$ never to $5=$ always $(\operatorname{coded} 1-3=0$ and $4-5=1) "$ \\
\hline Height & "How tall are you without your shoes on?" & $\mathrm{cm}$ \\
\hline Body weight & "How much do you weigh without your shoes on?" & $\mathrm{kg}$ \\
\hline
\end{tabular}




\section{Results}

\subsection{Sample Description}

The study sample consisted of 36173 school-going adolescents (with a median age of 14 years, interquartile range = 3) from Bangladesh, Indonesia, Laos, Philippines, Thailand, and Timor-Leste; the country response rates ranged from $72 \%$ to $94 \%$ [11]. Among the six study countries, the lowest number of participants was from Bangladesh $(\mathrm{N}=2989,8.3 \%)$ and the highest number from Indonesia $(\mathrm{N}=11142,30.8 \%$ ). The proportion of female students was $55.1 \%$ and male students $44.9 \%$, and $6.6 \%$ had mostly or always experienced hunger in the past month. About one in four of the students (26.9\%) had been in a physical fight in the past 12 months, 38.6\% had been attacked, 38.1\% had sustained a serious injury, $29.5 \%$ had been bullied, and $26.3 \%$ "missed classes or school without permission" in the past month. Regarding substance use, $13.2 \%$ of participants were current tobacco users, $10.5 \%$ current alcohol users, $10.2 \%$ had ever been drunk, 3.6\% had ever used cannabis, and $2.8 \%$ had ever used amphetamine. In terms of mental health, $10.0 \%$ of students reported loneliness, $6.8 \%$ anxiety, $7.5 \%$ suicide ideation, $8.1 \%$ had a suicide plan, and $8.6 \%$ had attempted suicide in the past 12 months. Two in five students (40.2\%) had almost always or always received peer support in the past month, $52.8 \%$ had medium or high parental support, $9.6 \%$ were underweight and $13.1 \%$ overweight or obese. In all six Southeast Asian countries, in the past 30 days $23.9 \%$ of participants had consumed no CSD, $38.8 \%$ had consumed CSD < once/day, $19.9 \%$ once a day and $17.5 \% \geq$ two times/day (see Table 2 ).

Table 2. Sample characteristics among adolescents in six Southeast Asian countries.

\begin{tabular}{|c|c|c|c|c|c|}
\hline Variable (\#Missing) & Sample & $\begin{array}{c}\text { Did Not Drink/Past } \\
30 \text { Days }\end{array}$ & $<1$ Time/Day & 1 Time/Day & $\geq 2$ Times/Day \\
\hline & N (\%) & $\%$ & $\%$ & $\%$ & $\%$ \\
\hline \multicolumn{6}{|l|}{ Sociodemographic } \\
\hline All & 36,173 & 23.9 & 38.8 & 19.9 & 17.5 \\
\hline \multicolumn{6}{|l|}{ Country $(\# 0)$} \\
\hline Bangladesh & $2989(8.3)$ & 15.7 & 37.1 & 18.6 & 28.6 \\
\hline Indonesia & $11,142(30.8)$ & 37.6 & 34.4 & 18.5 & 9.4 \\
\hline Laos & $3683(10.2)$ & 12.7 & 37.1 & 25.3 & 25.0 \\
\hline Philippines & $8761(24.2)$ & 12.2 & 50.6 & 20.0 & 17.2 \\
\hline Thailand & $5894(16.3)$ & 11.8 & 32.0 & 25.7 & 30.4 \\
\hline Timor-Leste & $3704(10.2)$ & 13.6 & 44.5 & 25.0 & 16.9 \\
\hline \multicolumn{6}{|l|}{ Age (years) (\#141) } \\
\hline$\leq 13$ & $10,327(34.3)$ & 27.9 & 34.3 & 21.0 & 16.8 \\
\hline 14 & $7919(26.0)$ & 23.7 & 37.9 & 20.2 & 18.2 \\
\hline 15 & 7348 (19.2) & 20.9 & 40.5 & 18.4 & 20.2 \\
\hline$\geq 16$ & $10,438(20.5)$ & 20.3 & 45.6 & 18.8 & 15.3 \\
\hline \multicolumn{6}{|l|}{ Gender (\#300) } \\
\hline Female & $19,779(55.1)$ & 27.0 & 38.1 & 19.2 & 15.7 \\
\hline Male & $16,094(44.9)$ & 20.9 & 39.5 & 20.5 & 19.2 \\
\hline Hunger (\#220) & $2346(6.6)$ & 5.3 & 6.2 & 7.1 & 8.2 \\
\hline \multicolumn{6}{|l|}{ Health Risk Behavior } \\
\hline In physical fight (\#215) & $9208(26.9)$ & 18.6 & 27.3 & 31.0 & 32.8 \\
\hline Physically attacked (\#309) & $11,960(38.6)$ & 30.6 & 39.9 & 41.4 & 42.9 \\
\hline Injury (\#5935) & $11,510(38.1)$ & 27.7 & 38.4 & 43.1 & 46.2 \\
\hline Bullied (\#2552) & $9890(29.5)$ & 21.0 & 31.5 & 32.7 & 32.9 \\
\hline School truancy (\#509) & $10,257(26.3)$ & 19.2 & 25.2 & 27.1 & 37.2 \\
\hline Current tobacco use (\#477) & $4812(13.2)$ & 9.1 & 13.2 & 13.5 & 18.1 \\
\hline Current alcohol use (\#1027) & 4909 (10.5) & 4.9 & 10.8 & 12.1 & 16.0 \\
\hline Ever drunkenness (\#1170) & $4349(10.2)$ & 5.0 & 10.6 & 11.6 & 14.9 \\
\hline Ever cannabis use (\#998) & $1296(3.6)$ & 2.5 & 3.5 & 3.9 & 5.1 \\
\hline $\begin{array}{l}\text { Ever amphetamine use } \\
(\# 1088)\end{array}$ & $985(2.8)$ & 2.1 & 2.7 & 2.9 & 3.9 \\
\hline Poor Mental Health & & & & & \\
\hline
\end{tabular}


Table 2. Cont.

\begin{tabular}{|c|c|c|c|c|c|}
\hline Variable (\#Missing) & Sample & $\begin{array}{c}\text { Did Not Drink/Past } \\
\text { 30 Days }\end{array}$ & $<1$ Time/Day & 1 Time/Day & $\geq 2$ Times/Day \\
\hline & $\mathrm{N}(\%)$ & $\%$ & $\%$ & $\%$ & $\%$ \\
\hline Loneliness (\#503) & $3657(10.0)$ & 8.3 & 9.5 & 9.3 & 13.7 \\
\hline Anxiety (\#212) & $2767(6.8)$ & 4.7 & 6.6 & 7.4 & 9.3 \\
\hline Suicide ideation (\#824) & $2758(7.5)$ & 6.0 & 6.9 & 7.4 & 10.8 \\
\hline Suicide plan (\#751) & $2927(8.1)$ & 6.7 & 7.7 & 8.1 & 11.1 \\
\hline Suicide attempt (\#199) & $3184(8.6)$ & 5.9 & 8.8 & 8.7 & 11.7 \\
\hline \multicolumn{6}{|l|}{ Confounding Factors } \\
\hline Peer support (\#654) & $12,906(40.2)$ & 40.9 & 39.5 & 39.2 & 41.7 \\
\hline \multicolumn{6}{|l|}{ Parental support (\#1411) } \\
\hline Low $(0-1)$ & $17,709(47.2)$ & 44.8 & 48.3 & 48.7 & 46.3 \\
\hline Medium (2) & $9428(27.7)$ & 28.1 & 26.9 & 25.3 & 31.7 \\
\hline High (3-4) & $7625(25.1)$ & 27.1 & 24.8 & 31.7 & 22.0 \\
\hline \multicolumn{6}{|l|}{ Body mass index (\#3325) } \\
\hline Normal & $25,743(77.3)$ & 75.5 & 78.7 & 76.4 & 77.4 \\
\hline Under & $3125(9.6)$ & 9.6 & 9.2 & 9.6 & 10.7 \\
\hline Overweight or obese & 3980 (13.1) & 14.9 & 12.1 & 14.0 & 12.0 \\
\hline
\end{tabular}

\subsection{Associations between CSD Intake and Aggression}

In the final adjusted logistic regression model, any, once and $\geq$ two times/day CSD intake was associated with increased odds of being attacked, in a physical fight, bullied and injured and of school truancy (see Table 3).

Table 3. Associations between soft drink use frequency and being attacked, in a physical fight, injury, being bullied, and truancy.

\begin{tabular}{|c|c|c|}
\hline Carbonated Soft Drink Consumption & AOR $(95 \% \text { CI })^{1}$ & AOR $(95 \% \mathrm{CI})^{2}$ \\
\hline & Attacked & Attacked \\
\hline Did not drink/past 30 days & 1 (Reference) & 1 (Reference) \\
\hline$<1$ time/day & $1.43(1.28,1.59) * * *$ & $1.41(1.27,1.57)^{* * *}$ \\
\hline 1 time/day & $1.59(1.42,1.78)^{* * *}$ & $1.53(1.35,1.74)^{* * *}$ \\
\hline \multirow[t]{2}{*}{$\geq 2$ times/day } & $1.47(1.22,1.76)^{* * *}$ & $1.51(1.26,1.82)^{* * *}$ \\
\hline & In physical fight & In physical fight \\
\hline Did not drink/past 30 days & 1 (Reference) & 1 (Reference) \\
\hline$<1$ time/day & $1.48(1.31,1.68)^{* * *}$ & $1.47(1.30,1.66)^{* * *}$ \\
\hline 1 time/day & $1.87(1.62,2.16)^{* * *}$ & $1.87(1.60,2.17)^{* * *}$ \\
\hline \multirow[t]{2}{*}{$\geq 2$ times/day } & $2.11(1.81,2.45)^{* * *}$ & $2.20(1.88,2.56)^{* * *}$ \\
\hline & Injury & Injury \\
\hline Did not drink/past 30 days & 1 (Reference) & 1 (Reference) \\
\hline$<1$ time/day & $1.36(1.18,1.55)^{* * * *}$ & $1.35(1.18,1.54)^{* * *}$ \\
\hline 1 time/day & $1.72(1.51,1.96)^{* * *}$ & $1.72(1.50,1.96)^{* * *}$ \\
\hline \multirow[t]{2}{*}{$\geq 2$ times/day } & $1.82(1.52,2.17)^{* * *}$ & $1.94(1.65,2.29)^{* * *}$ \\
\hline & Bullied & Bullied \\
\hline Did not drink/past 30 days & 1 (Reference) & 1 (Reference) \\
\hline$<1$ time/day & $1.31(1.17,1.47)^{* * * *}$ & $1.34(1.20,1.50)^{* * *}$ \\
\hline 1 time/day & $1.51(1.34,1.69) * * *$ & $1.48(1.30,1.68)^{* * *}$ \\
\hline \multirow[t]{2}{*}{$\geq 2$ times/day } & $1.49(1.27,1.75)^{* * *}$ & $1.51(1.28,1.78)^{* * *}$ \\
\hline & Truancy & Truancy \\
\hline Did not drink/past 30 days & 1 (Reference) & 1 (Reference) \\
\hline$<1$ time/day & $1.20(1.07,1.36) * *$ & $1.17(1.02,1.32) *$ \\
\hline 1 time/day & $1.41(1.23,1.62) * * *$ & $1.42(1.23,1.65)^{* * *}$ \\
\hline$\geq 2$ times/day & $2.18(1.84,2.59)^{* * *}$ & $2.27(1.93,2.68)^{* * *}$ \\
\hline
\end{tabular}

$\mathrm{AOR}=\mathrm{Adjusted}$ Odds Ratio; $\mathrm{CI}=$ Confidence Interval; ${ }^{1}$ adjusted for country only; ${ }^{2}$ adjusted for country, sex, age, hunger, body weight status, peer support and parental support; ${ }^{* * *} p<0.001,{ }^{* *} p<0.01,{ }^{*} p<0.05$. 


\subsection{Associations between CSD Intake and Substance Use}

In the final adjusted logistic regression model, any, once, and $\geq$ two times/day CSD intake was associated with increased odds of current tobacco use, current alcohol use, and ever been drunk. In addition, $\geq$ two times/day CSD intake was associated with increased odds of ever used cannabis and ever used amphetamine (see Table 4).

Table 4. Associations between soft drink use frequency and substance use.

\begin{tabular}{|c|c|c|}
\hline Carbonated Soft Drink Consumption & OR $(95 \% \text { CI })^{1}$ & $\operatorname{AOR}(95 \% \mathrm{CI})^{2}$ \\
\hline & Current tobacco use & Current tobacco use \\
\hline Did not drink/past 30 days & 1 (Reference) & 1 (Reference) \\
\hline$<1$ time/day & $1.51(1.24,1.85)^{* * *}$ & $1.44(1.16,1.17)^{* * *}$ \\
\hline 1 time/day & $1.58(1.28,1.95)^{* * *}$ & $1.63(1.31,2.03)^{* * *}$ \\
\hline \multirow[t]{2}{*}{$\geq 2$ times/day } & $2.40(1.83,3.15)^{* * *}$ & $2.68(2.03,3.53)^{* * *}$ \\
\hline & Current alcohol use & Current alcohol use \\
\hline Did not drink/past 30 days & 1 (Reference) & 1 (Reference) \\
\hline$<1$ time/day & $1.53(1.29,1.82) * * *$ & $1.62(1.38,1.90) * * *$ \\
\hline 1 time/day & $1.81(1.46,2.23) * * *$ & $2.09(1.77,2.48) * * *$ \\
\hline \multirow[t]{2}{*}{$\geq 2$ times/day } & $2.49(1.96,3.17) * * *$ & $2.90(2.40,3.50) * * *$ \\
\hline & Drunkenness & Drunkenness \\
\hline Did not drink/past 30 days & 1 (Reference) & 1 (Reference) \\
\hline$<1$ time/day & $1.41(1.15,1.72)^{* * *}$ & $1.54(1.32,1.80) * * *$ \\
\hline 1 time/day & $1.60(1.25,2.05)^{* * *}$ & $1.91(1.59,2.29) * * *$ \\
\hline \multirow[t]{2}{*}{$\geq 2$ times/day } & $2.07(1.61,2.66) * * *$ & $2.56(2.11,3.11)^{* * *}$ \\
\hline & Cannabis use & Cannabis use \\
\hline Did not drink/past 30 days & 1 (Reference) & 1 (Reference) \\
\hline$<1$ time/day & $0.92(0.66,1.28)$ & $1.05(0.69,1.59)$ \\
\hline 1 time/day & $1.08(0.71,1.62)$ & $1.41(0.94,2.13)$ \\
\hline \multirow[t]{2}{*}{$\geq 2$ times/day } & $1.38(0.88,2.14)$ & $1.97(1.36,2.87)^{* * *}$ \\
\hline & Amphetamine use & Amphetamine use \\
\hline Did not drink/past 30 days & 1 (Reference) & 1 (Reference) \\
\hline$<1$ time/day & $0.97(0.66,1.42)$ & $1.13(0.73,1.76)$ \\
\hline 1 time/day & $1.07(0.67,1.71)$ & $1.28(0.74,2.22)$ \\
\hline$\geq 2$ times/day & $1.42(0.83,2.44)$ & $2.14(1.27,3.62) * *$ \\
\hline
\end{tabular}

$\mathrm{AOR}=$ Adjusted Odds Ratio; $\mathrm{CI}=$ Confidence Interval; ${ }^{1}$ adjusted for country only; ${ }^{2}$ adjusted for country, sex, age, hunger, body weight status, peer support and parental support; ${ }^{* *} p<0.001,{ }^{* *} p<0.01,{ }^{*} p<0.05$.

\subsection{Associations between CSD Intake and Poor Mental Health}

In the final adjusted logistic regression model, $\geq$ two times/day CSD intake was associated with increased odds of loneliness, anxiety, suicide ideation, suicide plan, and suicide attempt (see Table 5). 
Table 5. Associations between soft drink use frequency and poor mental health.

\begin{tabular}{|c|c|c|}
\hline Carbonated Soft Drinks Consumption & OR $(95 \% \mathrm{CI})^{1}$ & $\operatorname{AOR}(95 \% \mathrm{CI})^{2}$ \\
\hline & Loneliness & Loneliness \\
\hline Did not drink/past 30 days & 1 (Reference) & 1 (Reference) \\
\hline$<1$ time/day & $0.87(0.74,1.01)$ & $0.90(0.76,1.04)$ \\
\hline 1 time/day & $0.92(0.77,1.09)$ & $0.99(0.81,1.20)$ \\
\hline \multirow[t]{2}{*}{$\geq 2$ times/day } & $1.34(1.07,1.66) * *$ & $1.38(1.09,1.72) * *$ \\
\hline & Anxiety & Anxiety \\
\hline Did not drink/past 30 days & 1 (Reference) & 1 (Reference) \\
\hline$<1$ time/day & $1.15(0.98,1.36)$ & $1.18(0.99,1.40)$ \\
\hline 1 time/day & $1.36(1.12,1.64) * *$ & $1.47(1.20,1.81)^{* * *}$ \\
\hline \multirow[t]{2}{*}{$\geq 2$ times/day } & $1.73(1.43,2.10)^{* * *}$ & $1.88(1.53,2.32) * * *$ \\
\hline & Suicide ideation & Suicide ideation \\
\hline Did not drink/past 30 days & 1 (Reference) & 1 (Reference) \\
\hline$<1$ time/day & $0.93(0.80,1.09)$ & $0.94(0.78,1.12)$ \\
\hline 1 time/day & $1.03(0.86,1.22)$ & $1.14(0.95,1.37)$ \\
\hline \multirow[t]{2}{*}{$\geq 2$ times/day } & $1.53(1.24,1.87)^{* * *}$ & $1.63(1.32,2.02)^{* * *}$ \\
\hline & Suicide plan & Suicide plan \\
\hline Did not drink/past 30 days & 1 (Reference) & 1 (Reference) \\
\hline$<1$ time/day & $0.95(0.82,1.10)$ & $0.95(0.80,1.13)$ \\
\hline 1 time/day & $1.01(0.85,1.20)$ & $1.08(0.90,1.31)$ \\
\hline \multirow[t]{2}{*}{$\geq 2$ times/day } & $1.34(1.11,1.62) * *$ & $1.41(1.15,1.74)^{* * *}$ \\
\hline & Suicide attempt & Suicide attempt \\
\hline Did not drink/past 30 days & 1 (Reference) & 1 (Reference) \\
\hline$<1$ time/day & $1.01(0.80,1.28)$ & $1.05(0.84,1.33)$ \\
\hline 1 time/day & $1.07(0.80,1.42)$ & $1.21(0.94,1.54)$ \\
\hline$\geq 2$ times/day & $1.37(1.04,1.82)$ * & $1.69(1.33,2.16)^{* * *}$ \\
\hline
\end{tabular}

$\mathrm{AOR}=$ Adjusted Odds Ratio; $\mathrm{CI}=$ Confidence Interval; ${ }^{1}$ adjusted for country only; ${ }^{2}$ adjusted for country, sex, age, hunger, body weight status, peer support, and parental support; ${ }^{* * *} p<0.001, * * p<0.01, * p<0.05$.

\section{Discussion}

The study found that across all six Southeast Asian countries (Bangladesh, Indonesia, Laos, Philippines, Thailand, and Timor-Leste) in 2014-2015, 23.9\% of participants had consumed no CSD in the past 30 days, $38.8 \%$ had consumed CSD <once/day, $19.9 \%$ once a day and $17.5 \% \geq$ two times/day. The consumption of CSD appears to be slightly higher than that reported in an earlier study conducted in Malaysia and the Maldives in 2009-2012 [12]. However, the prevalence of $\geq$ once CSD daily intake $(37.8 \%)$ in this study across six Southeast Asian countries was lower than the corresponding prevalence in 53 low- and middle-income countries (54.3\%) [12].

This study found a consistent association between CSD intake and health risk behaviors (being attacked, injury, in a physical fight, being bullied, school truancy, current tobacco use, current alcohol use, ever been drunk, ever used cannabis, and ever used amphetamine) and poor mental health (loneliness, anxiety, suicide ideation, suicide plan, and suicide attempt), independent off relevant confounders. These results are consistent with previous investigations in school-going adolescents in Europe (in terms of health risk behaviors: in a physical fight, smoking and alcohol use) [3], in USA, China, Korea and Malaysia in terms of physical fight, aggressive behavior $[4,5]$, substance use $[5,6]$, and injury [10]), and poor mental health (mental distress or depressive symptoms $[4,6,7,9]$ and suicidal behavior $[4,8])$. This result that soft drink consumption is accompanied by various health risk behaviors underlines the importance of tackling a clustering of CSD intake with a number of health risk behaviors and poor mental health in health promotion programs in this school population. 
The study found that associations between CSD intake and health risk behavior seem to be stronger than with poor mental health. It is possible that adolescents who are more sensation seeking engage more likely in frequent CSD intake and various health risk behaviors [7]. Another, possibility is that because CSD consumption is often initiated earlier (in childhood) [13] than substance use (in adolescence) and peer violence (in adolescence), early soft drink consumption may function as a "gateway" for later substance use [5]. From a problem behavior perspective during adolescence, Jessor and Jessor [14] deposit that problem behaviors, such as CSD intake, substance use and peer violence are interrelated and cluster together.

Carbonated soft drinks contain a high sugar content, and sugar has been found to associated with poor mental health, such as psychological distress and depression [15]. Several possible mechanisms for the relationship between sugar intake and psychological distress and depression have been proposed, e.g., "increased levels of $\beta$-endorphins and oxidative stress" [15,16]. Moreover, carbonated soft drinks often contain additives, such as caffeine [3]. Caffeine can "potentiate the addictive and toxic effects of drugs of abuse" [17], has been found to increase the risk for in a physical fight among adolescents [4], and was associated with anxiety and depression among school adolescents $[18,19]$.

\section{Study Limitations}

The study was limited by its cross-sectional design of a school population and measures using self-report. Several concepts in this study were assessed with single items, and future investigations may consider including more comprehensive measures. The study did also not assess dietary intake in terms of foods that are high in refined sugar content, such as candy and chocolate, which could be important in relation to sweetened beverage consumption.

\section{Conclusions}

Study results extend previous results from high-income countries showing an association between higher frequency of CSD intake and health risk behaviors (being attacked, injury, in a physical fight, being bullied, school truancy, current tobacco use, current alcohol use, ever been drunk, ever used cannabis, and ever used amphetamines) and poor mental health (loneliness, anxiety, and suicidal behavior), independent off relevant confounders. Frequent CSD intake and its associated health risk behaviors and poor mental health should be targeted in school health promotion interventions.

Author Contributions: S.P. and K.P. designed the analysis, analyzed the data, wrote the manuscript, and approved the paper. All authors have read and agreed to the published version of the manuscript.

Funding: This research received no external funding.

Acknowledgments: The World Health Organization is acknowledged for availing the datasets publicly for this analysis.

Conflicts of Interest: The authors declare that they have no conflict of interest.

\section{References}

1. Harrington, S. The role of sugar-sweetened beverage consumption in adolescent obesity: A review of the literature. J. Sch. Nurs. 2008, 24, 3-12. [CrossRef] [PubMed]

2. Vartanian, L.R.; Schwartz, M.B.; Brownell, K.D. Effects of soft drink consumption on nutrition and health: A systematic review and meta-analysis. Am. J. Public Health 2007, 97, 667-675. [CrossRef] [PubMed]

3. Bruckauf, Z.; Walsh, S.D. Adolescents' multiple and individual risk behaviors: Examining the link with excessive sugar consumption across 26 industrialized countries. Soc. Sci. Med. 2018, 216, 133-141. [CrossRef] [PubMed]

4. Solnick, S.J.; Hemenway, D. Soft drinks, aggression and suicidal behaviour in US high school students. Int. J. Inj. Control Saf. Promot. 2014, 21, 266-273. [CrossRef] [PubMed] 
5. Ziegler, A.M.; Temple, J.L. Soda consumption is associated with risk-taking behaviors in adolescents. Am. J. Health Behav. 2015, 39, 761-771. [CrossRef] [PubMed]

6. Terry-McElrath, Y.M.; O'Malley, P.M.; Johnston, L.D. Energy drinks, soft drinks, and substance use among United States secondary school students. J. Addict. Med. 2014, 8, 6-13. [CrossRef] [PubMed]

7. Pabayo, R.; Dias, J.; Hemenway, D.; Molnar, B.E. Sweetened beverage consumption is a risk factor for depressive symptoms among adolescents living in Boston, Massachusetts, USA. Public Health Nutr. 2016, 19, 3062-3069. [CrossRef] [PubMed]

8. Pan, X.; Zhang, C.; Shi, Z. Soft drink and sweet food consumption and suicidal behaviours among Chinese adolescents. Acta Paediatr. 2011, 100, e215-e222. [CrossRef] [PubMed]

9. Park, S.; Rim, S.J.; Lee, J.H. Associations between dietary behaviours and perceived physical and mental health status among Korean adolescents. Nutr. Diet. 2018, 75, 488-493. [CrossRef] [PubMed]

10. Peltzer, K.; Pengpid, S. Unintentional injuries and psychosocial correlates among in-school adolescents in Malaysia. Int. J. Environ. Res. Public Health 2015, 12, 14936-14947. [CrossRef] [PubMed]

11. World Health Organization (WHO). Global School-Based Student Health Survey (GSHS). 2019. Available online: https://www.who.int/ncds/surveillance/gshs/en/ (accessed on 2 March 2019).

12. Yang, L.; Bovet, P.; Liu, Y.; Zhao, M.; Ma, C.; Liang, Y.; Xi, B. Consumption of carbonated soft drinks among young adolescents aged 12 to 15 years in 53 low- and middle-income countries. Am. J. Public Health 2017, 107, 1095-1100. [CrossRef] [PubMed]

13. Han, E.; Powell, L.M. Consumption patterns of sugar-sweetened beverages in the United States. J. Acad. Nutr. Diet. 2013, 113, 43-53. [CrossRef] [PubMed]

14. Jessor, R.; Jessor, S. Problem Behaviour and Psychosocial Development: A Longitudinal Study of Youth; Academic Press: New York, NY, USA, 1997.

15. Westover, A.N.; Marangell, L.B. A cross-national relationship between sugar consumption and major depression? Depress. Anxiety 2002, 16, 118-120. [CrossRef] [PubMed]

16. Shi, Z.; Taylor, A.W.; Wittert, G.; Goldney, R.; Gill, T.K. Soft drink consumption and mental health problems among adults in Australia. Public Health Nutr. 2010, 13, 1073-1079. [CrossRef] [PubMed]

17. Ferré, S. Mechanisms of the psychostimulant effects of caffeine: Implications for substance use disorders. Psychopharmacology 2016, 233, 1963-1979. [CrossRef]

18. Richards, G.; Smith, A. Caffeine consumption and self-assessed stress, anxiety, and depression in secondary school children. J. Psychopharmacol. 2015, 29, 1236-1247. [CrossRef] [PubMed]

19. Jin, M.J.; Yoon, C.H.; Ko, H.J.; Kim, H.M.; Kim, A.S.; Moon, H.N.; Jung, S.P. The relationship of caffeine intake with depression, anxiety, stress, and sleep in Korean adolescents. Korean J. Fam. Med. 2016, 37, 111-116. [CrossRef] [PubMed]

(C) 2019 by the authors. Licensee MDPI, Basel, Switzerland. This article is an open access article distributed under the terms and conditions of the Creative Commons Attribution (CC BY) license (http://creativecommons.org/licenses/by/4.0/). 